\title{
Plant Proteins and Processes Targeted by Parasitic Nematode Effectors
}

\author{
Joffrey Mejias, Nhat My Truong ${ }^{\dagger}$, Pierre Abad, Bruno Favery and Michaël Quentin*
}

Centre National de la Recherche Scientifique, Institut National de la Recherche Agronomique, Institut Sophia Agrobiotech, Université Côte d'Azur, Sophia Antipolis, France

\section{OPEN ACCESS}

Edited by:

Mozhgan Sepehri,

Shiraz University, Iran

Reviewed by:

Tarek Hewezi,

The University of Tennessee,

United States

Reza Ghaderi,

Shiraz University, Iran

Godelieve Gheysen,

Ghent University, Belgium

Valerie Moroz Williamson,

University of California, Davis,

United States

*Correspondence:

Michaël Quentin

michael.quentin@inra.fr

tPresent address:

Nhat My Truong,

Faculty of Advanced Science and Technology, Kumamoto

University, Kumamoto, Japan

Specialty section:

This article was submitted to

Plant Microbe Interactions,

a section of the journal

Frontiers in Plant Science

Received: 17 May 2019

Accepted: 11 July 2019

Published: 30 July 2019

Citation:

Mejias J, Truong NM, Abad P, Favery B and Quentin M (2019) Plant Proteins and Processes Targeted by

Parasitic Nematode Effectors.

Front. Plant Sci. 10:970

doi: 10.3389/fpls.2019.00970
Sedentary endoparasitic nematodes, such as root-knot nematodes (RKN; Meloidogyne spp.) and cyst nematodes (CN; Heterodera spp. and Globodera spp.) cause considerable damage to agricultural crops. RKN and CN spend most of their life cycle in plant roots, in which they induce the formation of multinucleate hypertrophied feeding cells, called "giant cells" and "syncytia," respectively. The giant cells result from nuclear divisions of vascular cells without cytokinesis. They are surrounded by small dividing cells and they form a new organ within the root known as a root knot or gall. CN infection leads to the fusion of several root cells into a unique syncytium. These dramatically modified host cells act as metabolic sinks from which the nematode withdraws nutrients throughout its life, and they are thus essential for nematode development. Both RKN and $\mathrm{CN}$ secrete effector proteins that are synthesized in the oesophageal glands and delivered to the appropriate cell in the host plant via a syringe-like stylet, triggering the ontogenesis of the feeding structures. Within the plant cell or in the apoplast, effectors associate with specific host proteins, enabling them to hijack important processes for cell morphogenesis and physiology or immunity. Here, we review recent findings on the identification and functional characterization of plant targets of RKN and CN effectors. A better understanding of the molecular determinants of these biotrophic relationships would enable us to improve the yields of crops infected with parasitic nematodes and to expand our comprehension of root development.

Keywords: root-knot nematodes, cyst nematodes, galls, syncytium, effectors

\section{INTRODUCTION}

Plant-parasitic nematodes (PPN) are microscopic worms that withdraw nutrients from the cytoplasm of cells in the aerial or below-ground parts of plants. Root-knot nematodes (RKN) and cyst nematodes $(\mathrm{CN})$ are the most widely studied PPN, as these two groups are the most damaging to crop plants (Singh et al., 2013). RKN from the Meloidogyne genus are found throughout the world and are extremely polyphagous, infecting thousands of plant species, including both monocotyledons and eudicotyledons (Blok et al., 2008). By contrast, CN tend to specialize on a particular crop and form two common genera: Globodera spp. (potato CN) and Heterodera spp. (sugar beet, soybean, or cereal $\mathrm{CN}$ ), each of which causes huge yield losses on its host.

Both $\mathrm{CN}$ and RKN are sedentary endoparasites and obligate biotrophs. Mobile preparasitic juveniles (J2) penetrate the host root, traveling toward the vascular cylinder, where they become 
sedentary, triggering the formation of an unusual feeding site. The RKN feeding site consists of so-called "giant cells" (Figure 1A). These cells are produced from about half a dozen vascular root cells, which undergo repeated nuclear divisions without cell division. These cells become polynucleate and may be more than 300 times larger than normal cells. Giant cells are surrounded by dividing cells, the hyperplasia and hypertrophy of which lead to the formation of a novel organ called a gall (Kyndt et al., 2013; Favery et al., 2016; PalomaresRius et al., 2017). By contrast, $\mathrm{CN}$ induce the formation of a different type of feeding site called a syncytium. Syncytium formation involves partial dissolution of the root cell wall and protoplast fusion, leading to an iterative process of fusion of the first $\mathrm{CN}$-infested vascular cell with its neighbors (Figure 1B; Sobczak and Golinowski, 2011; Palomares-Rius et al., 2017). Some mature syncytia are the result of fusions of more than 200 cells. Giant cells and syncytia have a number of features in common, including a fully expanded endoplasmic reticulum, a fragmented vacuole, a reorganized cytoskeleton, thickened cell walls with local ingrowths, a large mitochondrial network and endoreduplicated nuclei (Kyndt et al., 2013; Rodiuc et al., 2014). These specialized feeding cells supply the nematodes with nutrients throughout the sedentary part of their life cycle. Female RKN lay their eggs in a gelatinous matrix generally on the root surface, whereas the cyst of CN consists of a dead and hardened female containing eggs.

Root-knot nematodes and CN secrete molecules called "effectors," to facilitate invasion of the host root, avoid plant defense responses and reprogram root cells to form specialized feeding cells. These effectors are produced principally in three oesophageal salivary glands and are then injected into plant cells via the syringe-like stylet. The activity of the oesophageal glands is developmentally regulated. The two subventral glands (SvG) secrete effectors allowing J2 penetration and migration in the root while proteins secreted during parasitism are produced by SvG and particularly by the dorsal gland (DG) (Nguyen et al., 2018). Some effectors may also be produced in other secretory organs, such as chemosensory amphids, or directly secreted through the PPN cuticle. Molecular dialog studies have focused mostly on secreted proteinaceous effectors (Hewezi and Baum, 2013; Mitchum et al., 2013; Quentin et al., 2013; Hewezi, 2015; Ali et al., 2017; Vieira and Gleason, 2019) even though other secreted molecules, such as phytohormones, have been shown to favor these interactions (Siddique and Grundler, 2018).

Various approaches have been used to characterize nematode effector repertoires. Proteomic analysis has directly identified about 500 proteins secreted by $M$. incognita preparasitic J2s or females (Bellafiore et al., 2008; Wang et al., 2012). Effector identification has greatly benefited from advances in sequencing technologies. Complete genome sequences are now available for four RKN - M. incognita, M. hapla, M. javanica, and M. arenaria (Abad et al., 2008; Opperman et al., 2008; BlancMathieu et al., 2017) - and three CN: G. pallida, G. rostochiensis, and $H$. glycines (Cotton et al., 2014; Eves-van den Akker et al., 2016; Masonbrink et al., 2019). Bioinformatic methods for identifying genes encoding putative secreted proteins, which are based on the presence of a signal peptide for secretion but absence of transmembrane domains, remain the most convenient approach to identify candidate effector genes. Cis-regulatory sequences called "DOG boxes" were recently identified within the promoters of $G$. rostochiensis and $H$. glycines genes encoding effectors specifically expressed within the DG of the CN (Evesvan den Akker et al., 2016; Masonbrink et al., 2019). This discovery opens up new possibilities for effector prediction and implies that effector production in the DG is synchronized by master regulators, such as key transcription factors (Eves-van den Akker and Birch, 2016). Finally, transcriptomics has made it possible to compare different stages of nematode development and to identify RKN (Li et al., 2016; Petitot et al., 2016; Nguyen et al., 2018; Shukla et al., 2018) and CN (Cotton et al., 2014; Kumar et al., 2014; Yang et al., 2017; Gardner et al., 2018) genes upregulated in plants. In situ hybridisation (ISH) has generally been used for the initial validation of candidate effector gene expression within secretory organs (Figure 1C and Table 1). Remarkably, the secretion of a few effectors has been demonstrated in planta, by immunolocalisation (Table 1). Delivery to the host apoplast has been demonstrated for several effectors (Jaubert et al., 2005; Vieira et al., 2011; Iberkleid et al., 2013; Eves-van den Akker et al., 2014; Zhuo et al., 2019), but few demonstrations of translocation into the host feeding cell have been reported (Jaouannet et al., 2012; Lin et al., 2012; Chen et al., 2017; Lilley et al., 2018; Naalden et al., 2018). These studies have expanded the repertoire of putative effectors considerably, with hundreds of ISH-validated effectors now known (Truong et al., 2015; Gardner et al., 2016). However, the vast majority of these proteins are pioneer proteins with no known functional domains. As a result, the functions of only a few RKN and $\mathrm{CN}$ effectors have been deciphered. Cell wall-degrading effectors have been reported to help nematodes to penetrate and migrate within the root, and effectors suppressing plant defenses have been described (Quentin et al., 2013; Goverse and Smant, 2014), but only a few effectors have been shown to contribute to the de novo organogenesis and maintenance of feeding sites. Functional analyses of PPN effectors have clearly benefited from the identification of the host targets of these molecules, mostly through yeast two-hybrid approaches (Table 1). We review here the most recent advances in our understanding of RKN and CN effector functions, focusing on those for which the plant processes targeted have been identified.

\section{PARASITISM REQUIRES THE MANIPULATION OF DIVERSE HOST FUNCTIONS}

Nematode effectors target the apoplast and different subcellular compartments, including the nuclei, reflecting the diversity of host cell processes manipulated to promote infection and feeding site formation (Table 1). Many of the members of the PPN effector repertoire have been shown to suppress plant immunity (Goverse and Smant, 2014; Favery et al., 2016; Ali et al., 2017). However, their precise mode of action remains largely unknown and only a few of their direct targets in plants 

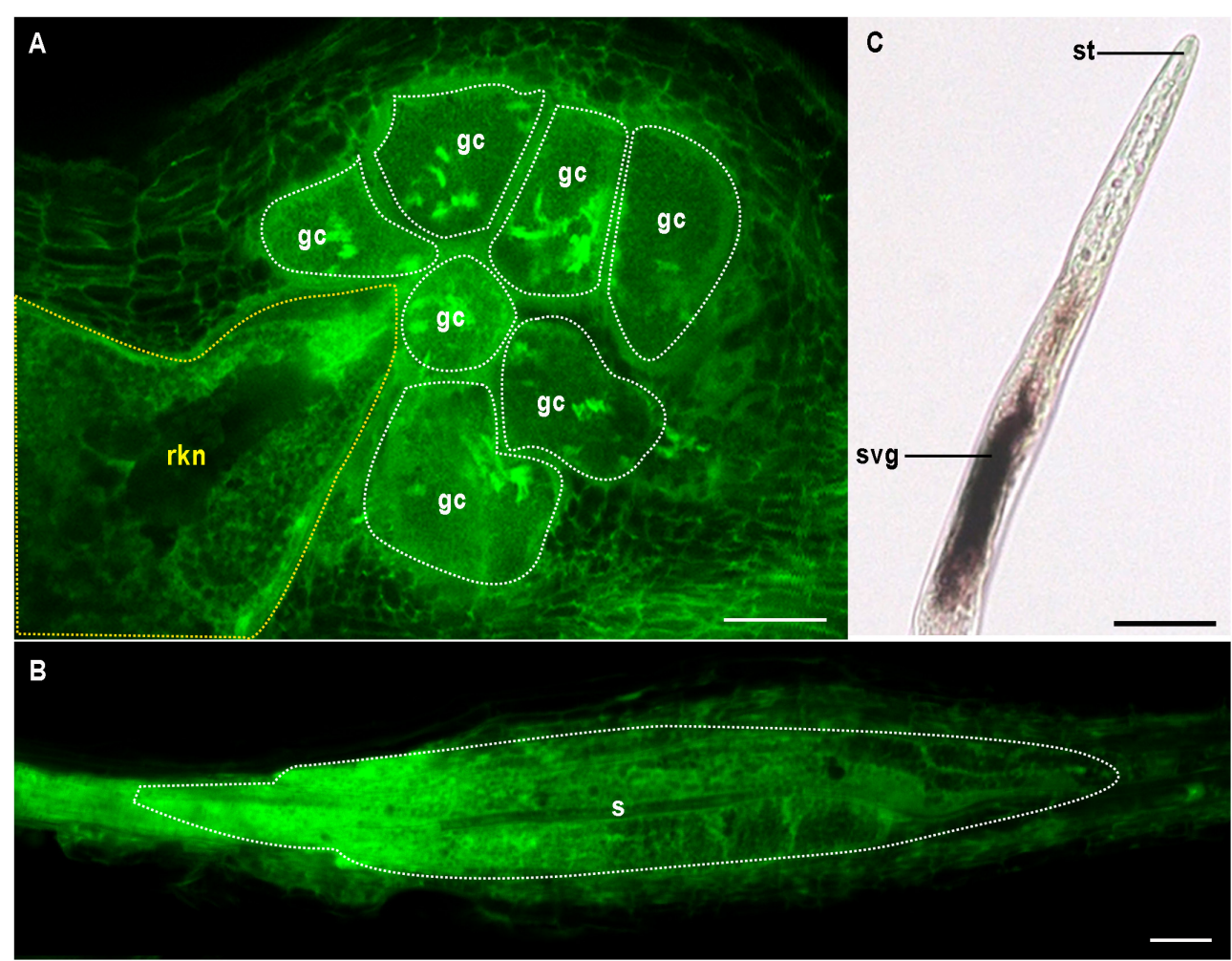

FIGURE 1 | Multinucleate and hypertrophied feeding cells induced by endoparasitic plant nematodes. (A) Giant cells (gc and white outline) induced by the root-knot nematode Meloidogyne incognita (rkn and yellow outline) in Arabidopsis thaliana. (B) Syncytium (s and white outline) formed by the cyst nematode Heterodera schachtii in A. thaliana. (A,B) confocal images were obtained by visualizing glutaraldehyde fixative auto-fluorescence after BABB clearing as described in Cabrera et al. (2018). (C) In situ hybridisation of the pioneer M. incognita effector gene Minc16401 encoding a predicted peptide of 69 amino acids (Abad et al., 2008) was performed as described in Jaouannet et al. (2018). Minc16401 expression was localized in subventral glands (svg), suggesting the effector could be secreted in planta via the stylet (st). Bars $=50 \mu \mathrm{m}$.

have been identified. PPN effectors may interact with host proteins to scavenge reactive oxygen species (ROS) accumulating during the oxidative burst following the induction of pathogenassociated molecular pattern (PAMP)-triggered immunity (PTI). M. javanica MjTTL5 scavenges ROS by interacting with a thioredoxin reductase catalytic subunit (AtFTRc) in the plant (Lin et al., 2016). H. schachtii Hs10A06 has been shown to interact with a spermidine synthase (AtSPDS2), thereby enhancing spermidine production and inducing ROS-scavenging activity when the spermidine is oxidized by polyamine oxidase (Hewezi et al., 2010). Various pathogenesis-related (PR) proteins involved in the production of antimicrobial proteins by plants in response to pathogen attack have also been identified as direct targets of nematode effectors. H. glycines $\mathrm{Hg} 30 \mathrm{C} 02$ targets a beta-1,3-endoglucanase (AtPR2), the inactivation of which in a mutant Arabidopsis line increases susceptibility to cyst nematode infection (Hamamouch et al., 2012). M. graminicola MgMO237 has been shown to suppress PTI by interacting with multiple host PR proteins, a 1,3-beta-glucan synthase (OsGSC), the cysteine-rich repeat secretory protein 55 (OsCRRSP55) and a pathogenesis-related Bet v I family protein (OsBetvI) (Chen et al., 2018). The GrVAP-1 effector from G. rostochiensis targets an apoplastic papain-like cysteine protein (PLCP) called

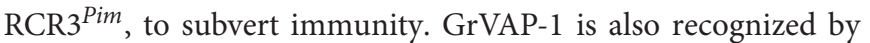
a plant immune receptor called Cf- 2 that can trigger effectortriggered immunity (ETI) followed by a hypersensitive response (Lozano-Torres et al., 2012).

Like other classes of plant pathogens that have to overcome host defenses, PPNs produce effectors that converge on evolutionarily conserved host targets called "hubs" (Carella et al., 2018). The M. incognita "Passe-Muraille" peptide effector, for example, interacts with subunit 5 of the COP9 signalosome (CSN5) (Bournaud et al., 2018), a hub targeted by bacterial, fungal and viral effectors (Mukhtar et al., 2011; Weßling et al., 2014). The function of CSN5 in RKN parasitism remains unknown, but this target protein is known to be involved in plant salicylic acid-mediated defense (Kazan and Lyons, 2014). Similarly, the H. schachtii Hs25A01 effector interacts with eIF2bs, a member of the eIFs family of translation initiation factors including known host targets of fungi, bacteria and viruses, and a role for this target in parasitism was demonstrated by the observation of changes in susceptibility to nematodes in eIF-2bs knockout mutants (Pogorelko et al., 2016). A third striking example is provided by PLCPs, which constitute key hubs in plant immunity (Misas-Villamil et al., 2016). PLCPs are targeted by M. chitwoodi Mc01194 (Davies et al., 2015) and 


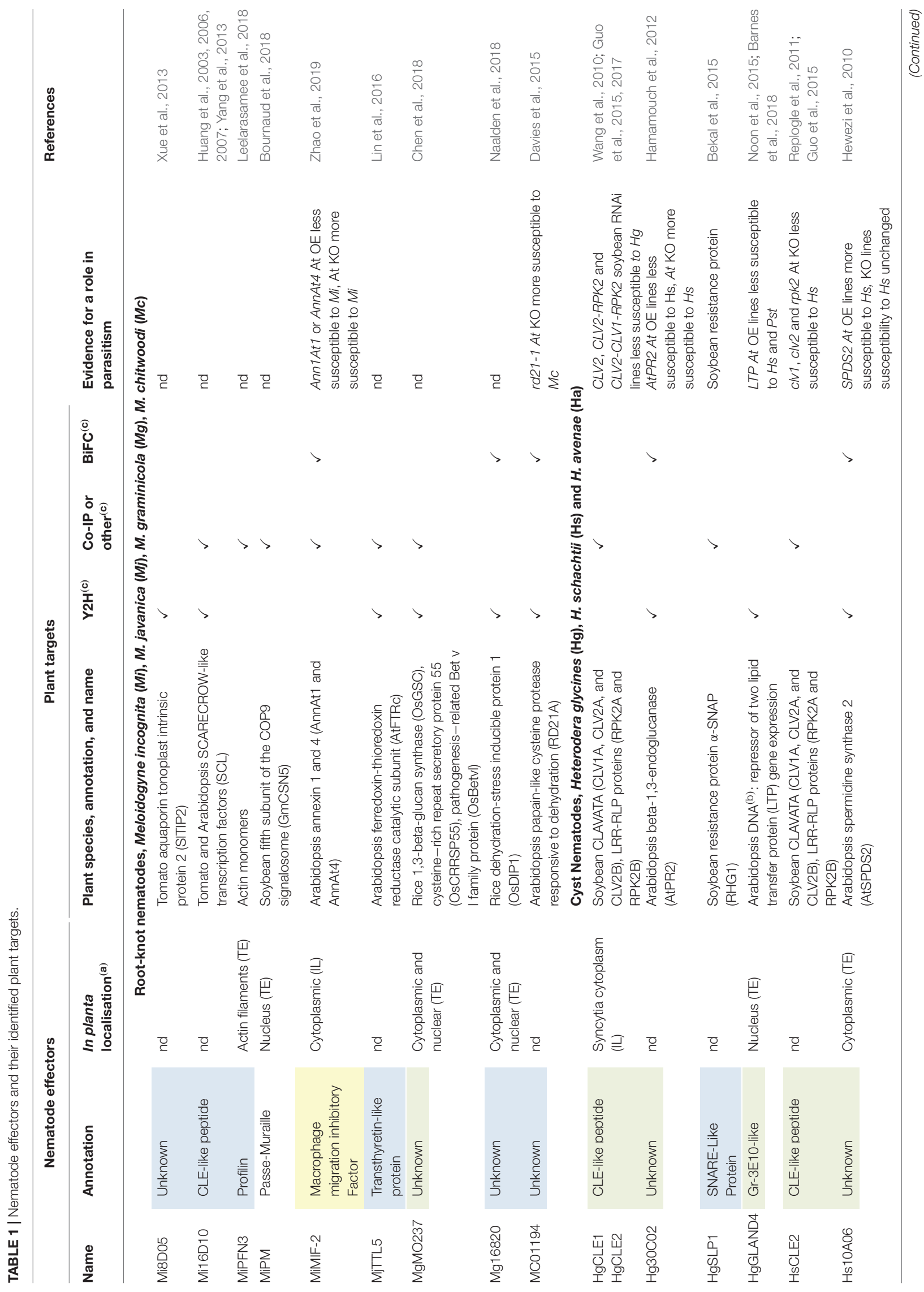




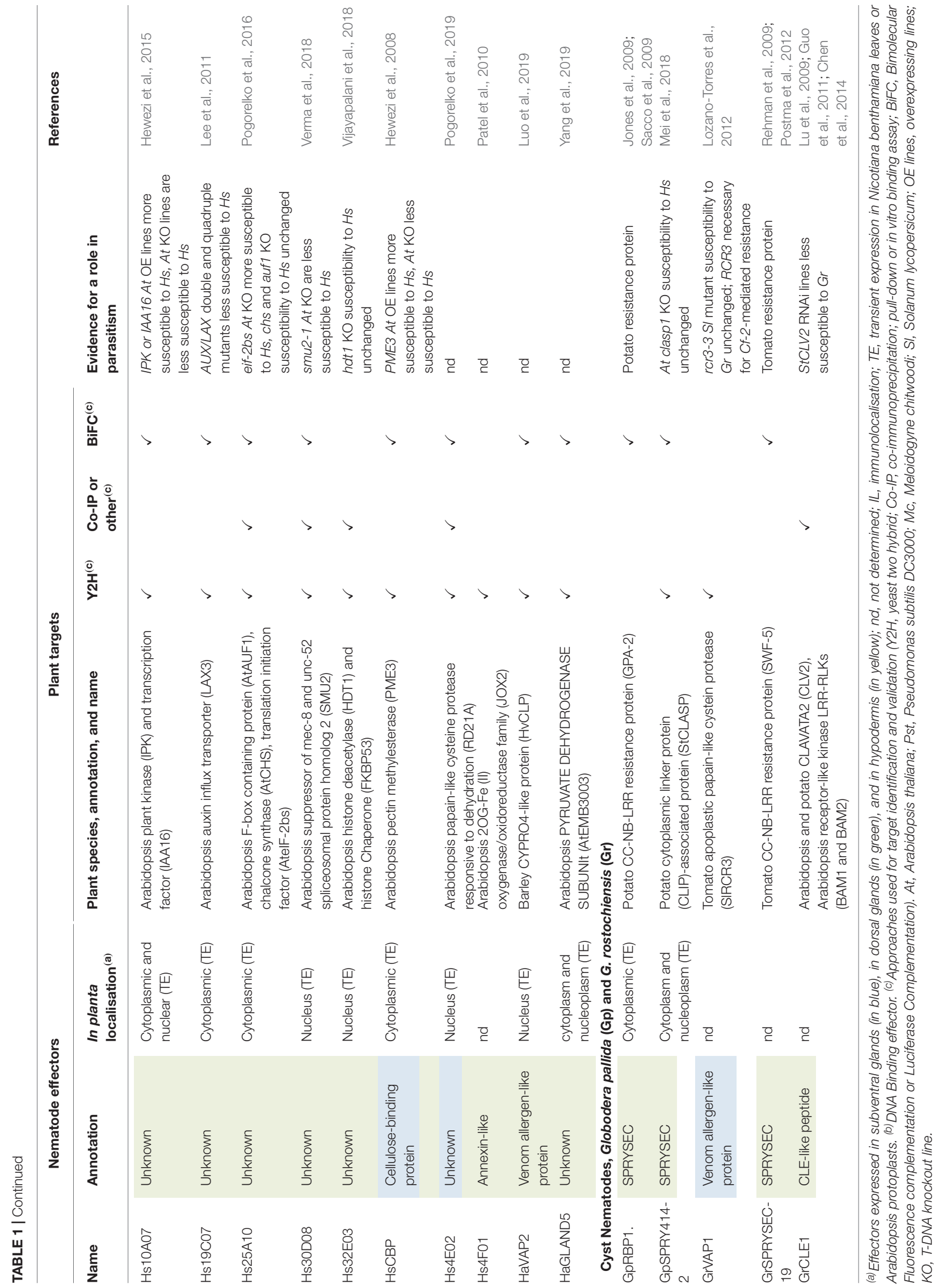


CN G. rostochiensis GrVAP-1 and H. schachtii Hs4E02 (LozanoTorres et al., 2012; Pogorelko et al., 2019) effectors in diverse host plants. Mc01194 and Hs4E02 target the same Arabidopsis PLCP, "Responsive to Dehydration 21A" (RD21A), to promote parasitism (Davies et al., 2015; Pogorelko et al., 2019). The expression of $G$. rostochiensis VAP1, which targets RCR3 ${ }^{\text {Pim }}$ in tomato, promotes susceptibility to $G$. rostochiensis and to the leaf mold Cladosporium fulvum (Lozano-Torres et al., 2012). It seems likely that other such molecular hubs are targeted by nematode effectors.

Other host functions targeted by RKN and $\mathrm{CN}$ effectors may be more related to the de novo formation and functioning of the specialized feeding site. The formation of feeding cells induced by $\mathrm{RKN}$ and $\mathrm{CN}$ requires a major reorganization of cytoskeletal networks (de Almeida Engler and Favery, 2011). RKN have been reported to secrete cytoskeleton components, such as actin or tubulin (Bellafiore et al., 2008), or associated proteins. A $M$. incognita profilin-like effector, MiPFN3, was recently shown to bind actin, altering its filament structure to favor parasitism (Leelarasamee et al., 2018). The G. pallida GpSPRY-414-2 effector, a CN-specific secreted SPRY domaincontaining protein (SPRYSEC), has been shown to bind a potato microtubule-associated protein, CLASP (for cytoplasmic linker protein-associated protein) (Mei et al., 2018). CLASP proteins are involved in both cell division and cell expansion (Ambrose et al., 2007). GpSRY-414-2 therefore probably modulates the microtubule network in syncytia. New specific screens should identify new effectors targeting this key process for cell morphogenesis and pathogen response.

Finally, several RKN and CN effectors have been characterized that mimic and/or interfere with plant hormone peptide pathways (recently reviewed by Gheysen and Mitchum, 2019). Several CN effectors resemble the CLAVATA3 (CLV3)/ESR (CLE) hormones involved in controlling cell proliferation and differentiation. In vitro binding assays have confirmed the interaction of these CLE-like effectors with known receptors of plant CLE-peptides, such as CLAVATA2 (CLV2). The secretion of such hormone-mimicking peptides enables PPN to modulate root cell hormonal balance to promote feeding site formation. Additional effectors, such as the H. schachtii Hs19C07 and Hs10A07, have been shown to modulate auxin signaling, by interacting with the auxin transporter LAX3 (Lee et al., 2011), and by affecting the expression of auxin-responsive factors (ARFs) (Hewezi et al., 2015; see below), respectively, to facilitate feeding site formation.

\section{HOST CELL REPROGRAMMING THROUGH THE MODULATION OF GENE EXPRESSION}

The morphological, structural and metabolic changes associated with the ontogenesis of nematode feeding cells require the extensive reprogramming of plant gene expression (Szakasits et al., 2009; Favery et al., 2016). Gene expression is regulated principally in the nucleus, and several effectors are thought to target the nuclei of the cells destined to become feeding cells, as they have predicted plant-like nuclear or nucleolar localisation signals, and some have been detected in the nucleus following ectopic expression in Nicotiana benthamiana leaves. Nuclear translocation in host cells has been demonstrated by immunolocalisation for only three RKN effectors: the M. incognita MiEFF1 (Jaouannet et al., 2012) and the M. javanica MjNULG1a (Lin et al., 2012) of unknown functions, and the M. graminicola MgGPP involved in plant defense suppression (Chen et al., 2017). All three were localized to giant cell nuclei. However, the targets of these effectors have yet to be characterized. Interestingly, some $\mathrm{RKN}$ and $\mathrm{CN}$ effectors have been shown to target key regulatory processes, including the epigenetic modification of histones, transcriptional regulation and mRNA splicing.

The Hs32E03 effector of $H$. schachtii alters the acetylation of histones by interacting with the Arabidopsis histone deacetylase (HDAC) HDT1 and FK506 binding protein, FKBP53 (Vijayapalani et al., 2018) in the nucleus. HDT1 and FKBP53 repress the transcription of rRNA genes, with HDT1 deacetylating histone $\mathrm{H} 3$ at Lys-9. Hs32E03 has been shown to inhibit HDAC, and an assessment of histone modifications in Hs32E03-expressing Arabidopsis lines based on chromatin immunoprecipitation revealed that these lines had abnormally high levels of acetylation in rDNA regions. As expected, rRNA levels were high in the line showing a low expression of Hs32E03 and displaying higher levels of $\mathrm{CN}$ infection. Interestingly, lower levels of rRNA were detected in the line highly expressing Hs32E03, due to the hypermethylation of rDNA promoters, resulting in an inhibition of nematode development. These findings highlight the importance of rRNA levels for syncytium formation, as protein overproduction is required, which in turn necessitates the synthesis of additional ribosomes. Hs32E03 is the first nematode effector for which a role has been reported in the epigenetic regulation of plant gene expression to promote parasitism.

Several other nuclear effectors have been shown to target transcription factors directly. The M. incognita Mi16D10 effector, which has a C-terminal CLE-like domain, interacts with SCARECROW-like transcription factors from both tomato and Arabidopsis (Huang et al., 2006). SCARECROW transcription factors are involved in root radial patterning, particularly in endoderm differentiation, and they act in concert with a short root transcription (SHR) factor (Hirsch and Oldroyd, 2009). Plants overexpressing Mi16D10 have larger root systems, implicating this effector in the modulation of root development. Another example is provided by the $H$. schachtii effector Hs10A07, which is secreted into the cytoplasm and then phosphorylated by an Arabidopsis kinase. This phosphorylation leads to its translocation into the nucleus, where it interacts with a second protein, IAA16, an Aux/IAA transcription factor, to modulate ARF expression (Hewezi et al., 2015).

Other effectors may modulate gene transcription directly by binding to DNA. Examples include $H$. glycines HgGLAND4 (Barnes et al., 2018) and the M. incognita 7H08 effector (Zhang et al., 2015). HgGLAND4 has been shown to bind specifically to the promoters of LTP genes implicated in plant defense, suppressing their expression (Barnes et al., 2018). Mi7H08 
has been shown to be imported into the nucleus, and to activate the transcription of a reporter gene in planta, but the host genes regulated by this effector have yet to be identified (Zhang et al., 2015).

Finally, a $H$. schachtii effector, Hs30D08, has been shown to interfere with mRNA splicing, thereby altering gene expression in feeding sites (Verma et al., 2018). RNA splicing is required to remove introns from pre-mRNA and to join the protein-coding sequences (exons) together during the translation of mRNA into protein. Alternative splicing (AS) may occur, and this represents another way of regulating gene expression and increasing protein diversity. In Arabidopsis, $70 \%$ of genes may be alternatively spliced, and AS has been shown to play a significant role in plant development, and in responses to abiotic and biotic stresses (Reddy et al., 2013; Yang et al., 2014). Hs30D08 has been shown to interact with an actor of the spliceosome machinery, the auxiliary spliceosomal protein SMU2, in Arabidopsis (Verma et al., 2018). Transcriptomic analyses of Arabidopsis lines expressing the Hs30D08 confirmed its function in modulating AS and gene expression. Future investigations will shed light on the role of splicing and AS in feeding cell formation and plant responses to $\mathrm{CN}$ and $\mathrm{RKN}$.

\section{CONCLUSION AND PERSPECTIVES}

The repertoire of putative $\mathrm{RKN}$ and $\mathrm{CN}$ effectors is extremely large, and proteinaceous effectors have been shown to target diverse compartments, manipulating many host plant functions to orchestrate the suppression of plant defenses, the formation of feeding sites and the promotion of nematode survival and reproduction. Moreover, the arsenal of plant pathogens is not restricted to proteinaceous effectors. They also secrete other molecules, such as secondary metabolites, glycolipids, hormones analogs, or small RNAs, to alter plant functions (Weiberg et al., 2013; Manosalva et al., 2015; Collemare et al., 2019). However, few data are available concerning the functions of effectors and the plant processes they target. The elucidation of effector function and the identification of host targets during parasitism thus remain major challenges. The large-scale identification of effector targets, particularly in crops, would be an important breakthrough potentially leading to the discovery of new processes involved in plant-nematode dialog. Comparison

\section{REFERENCES}

Abad, P., Gouzy, J., Aury, J.-M., Castagnone-Sereno, P., Danchin, E. G. J., Deleury, E., et al. (2008). Genome sequence of the metazoan plant-parasitic nematode Meloidogyne incognita. Nat. Biotechnol. 26, 909-915. doi: 10.1038/nbt.1482

Ali, M. A., Azeem, F., Li, H., and Bohlmann, H. (2017). Smart parasitic nematodes use multifaceted strategies to parasitize plants. Front. Plant Sci. 8:1699. doi: 10.3389/fpls.2017.01699

Ambrose, J. C., Shoji, T., Kotzer, A. M., Pighin, J. A., and Wasteneys, G. O. (2007). The Arabidopsis CLASP gene encodes a microtubule-associated protein involved in cell expansion and division. Plant Cell 19, 2763-2775. doi: 10.1105/ tpc.107.053777

Barnes, S. N., Wram, C. L., Mitchum, M. G., and Baum, T. J. (2018). The plantparasitic cyst nematode effector GLAND4 is a DNA-binding protein. Mol. Plant Pathol. 19, 2263-2276. doi: 10.1111/mpp.12697 of RKN- and CN-targets will shed light on processes involved in their specific parasitic strategies and host ranges.

Functional analyses of effector targets may lead to the identification of susceptibility genes with potential for use in resistance breeding (De Almeida Engler et al., 2005; van Schie and Takken, 2014). In addition, "hubs," susceptibility factors frequently targeted by different pathogens, may constitute ideal candidates for the design of broad-host range resistance in plants. However, these susceptibility genes are often crucial for plant physiology and development. Interfering with host protein recognition by pathogen effectors may be an interesting way of preserving important plant functions whilst breaking the susceptibility of the plant to pathogens. The breeding of new crops harboring point mutations that are less susceptible to diseases may be achieved with new technologies, such as the TILLING and CRISPR/Cas9 technologies, which are increasingly widely used (Engelhardt et al., 2018; Zaidi et al., 2018). Improvements in our understanding of effector/target functions are required if we are to block plant-microbe compatible interactions and engineer durable disease resistance.

\section{AUTHOR CONTRIBUTIONS}

All authors wrote the manuscript and approved it for publication.

\section{FUNDING}

JM benefits from a doctoral fellowship of the Ministère de l'Enseignement Supérieur, de la Recherche et de l'Innovation (MENRT grant). NT was supported by a USTH fellowship, 911USTH program, from the Ministry of Education and Training of The Socialist Republic of Vietnam. PA, BF, and MQ are supported by INRA and by the French Government (National Research Agency, ANR) through the "Investments for the Future" LabEx SIGNALIFE: program reference \#ANR-11-LABX-0028-01.

\section{ACKNOWLEDGMENTS}

We wish to thank Javier Cabrera and Carolina Escobar (UCLM, Toledo, Spain) for providing the syncytium picture.

Bekal, S., Domier, L. L., Gonfa, B., Lakhssassi, N., Meksem, K., and Lambert, K. N. (2015). A SNARE-like protein and biotin are implicated in soybean cyst nematode virulence. PLoS One 10:e0145601. doi: 10.1371/journal.pone. 0145601

Bellafiore, S., Shen, Z., Rosso, M.-N., Abad, P., Shih, P., and Briggs, S. P. (2008). Direct identification of the Meloidogyne incognita secretome reveals proteins with host cell reprogramming potential. PLoS Pathog. 4:e1000192. doi: 10.1371/ journal.ppat.1000192

Blanc-Mathieu, R., Perfus-Barbeoch, L., Aury, J.-M., Da Rocha, M., Gouzy, J., Sallet, E., et al. (2017). Hybridization and polyploidy enable genomic plasticity without sex in the most devastating plant-parasitic nematodes. PLoS Genet. 13:e1006777. doi: 10.1371/journal.pgen.1006777

Blok, V. C., Jones, J. T., Phillips, M. S., and Trudgill, D. L. (2008). Parasitism genes and host range disparities in biotrophic nematodes: the conundrum of polyphagy versus specialisation. Bioessays 30, 249-259. doi: 10.1002/bies.20717 
Bournaud, C., Gillet, F.-X., Murad, A. M., Bresso, E., Albuquerque, E. V. S., and Grossi-de-Sá, M. F. (2018). Meloidogyne incognita PASSE-MURAILLE (MiPM) gene encodes a cell-penetrating protein that interacts with the CSN5 subunit of the COP9 signalosome. Front. Plant Sci. 9:904. doi: 10.3389/fpls.2018.00904

Cabrera, J., Olmo, R., Ruiz-Ferrer, V., Abreu, I., Hermans, C., Martinez-Argudo, I., et al. (2018). A phenotyping method of giant cells from root-knot nematode feeding sites by confocal microscopy highlights a role for CHITINASE-LIKE 1 in Arabidopsis. Int. J. Mol. Sci. 19:429. doi: 10.3390/ijms19020429

Carella, P., Evangelisti, E., and Schornack, S. (2018). Sticking to it: phytopathogen effector molecules may converge on evolutionarily conserved host targets in green plants. Curr. Opin. Plant Biol. 44, 175-180. doi: 10.1016/j.pbi.2018.04.019

Chen, J., Hu, L., Sun, L., Lin, B., Huang, K., Zhuo, K., et al. (2018). A novel Meloidogyne graminicola effector, MgMO237, interacts with multiple host defence-related proteins to manipulate plant basal immunity and promote parasitism. Mol. Plant Pathol. 19, 1942-1955. doi: 10.1111/mpp.12671

Chen, J., Lin, B., Huang, Q., Hu, L., Zhuo, K., and Liao, J. (2017). A novel Meloidogyne graminicola effector, MgGPP, is secreted into host cells and undergoes glycosylation in concert with proteolysis to suppress plant defenses and promote parasitism. PLoS Pathog. 13:e1006301. doi: 10.1371/journal.ppat. 1006301

Chen, S., Lang, P., Chronis, D., Zhang, S., De Jong, W. S., Mitchum, M. G., et al. (2014). In Planta processing and glycosylation of a nematode CLAVATA3/ENDOSPERM SURROUNDING REGION-like effector and its interaction with a host CLAVATA2-like receptor to promote parasitism. Plant Physiol. 167, 262-272. doi: 10.1104/pp.114.251637

Collemare, J., O'Connell, R., and Lebrun, M. (2019). Nonproteinaceous effectors: the terra incognita of plant-fungal interactions. New Phytol. 223, 590-596. doi: 10.1111/nph.15785

Cotton, J. A., Lilley, C. J., Jones, L. M., Kikuchi, T., Reid, A. J., Thorpe, P., et al. (2014). The genome and life-stage specific transcriptomes of Globodera pallida elucidate key aspects of plant parasitism by a cyst nematode. Genome Biol. 15:R43. doi: 10.1186/gb-2014-15-3-r43

Davies, L. J., Zhang, L., and Elling, A. A. (2015). The Arabidopsis thaliana papainlike cysteine protease RD21 interacts with a root-knot nematode effector protein. Nematology 17, 655-666. doi: 10.1163/15685411-00002897

de Almeida Engler, J., and Favery, B. (2011). “The plant cytoskeleton remodelling in nematode induced feeding sites," in Genomics and Molecular Genetics of PlantNematode Interactions, eds J. Jones, G. Gheysen, and C. Fenoll (Dordrecht: Springer), 369-393. doi: 10.1007/978-94-007-0434-3_18

De Almeida Engler, J., Favery, B., Engler, G., and Abad, P. (2005). Loss of susceptibility as an alternative for nematode resistance. Curr. Opin. Biotechnol. 16, 112-117. doi: 10.1016/j.copbio.2005.01.009

Engelhardt, S., Stam, R., Hückelhoven, R., Engelhardt, S., Stam, R., and Hückelhoven, R. (2018). Good riddance? Breaking disease susceptibility in the era of new breeding technologies. Agronomy 8:114. doi: 10.3390/ agronomy 8070114

Eves-van den Akker, S., and Birch, P. R. J. (2016). Opening the effector protein toolbox for plant-parasitic cyst nematode interactions. Mol. Plant 9, 14511453. doi: 10.1016/j.molp.2016.09.008

Eves-van den Akker, S., Laetsch, D. R., Thorpe, P., Lilley, C. J., Danchin, E. G. J., Da Rocha, M., et al. (2016). The genome of the yellow potato cyst nematode, Globodera rostochiensis, reveals insights into the basis of parasitism and virulence. Genome Biol. 17:124. doi: 10.1186/s13059-016-0985-1

Eves-van den Akker, S., Lilley, C. J., Jones, J. T., and Urwin, P. E. (2014). Identification and characterisation of a hyper-variable apoplastic effector gene family of the potato cyst nematodes. PLoS Pathog. 10:e1004391. doi: 10.1371/ journal.ppat.1004391

Favery, B., Quentin, M., Jaubert-Possamai, S., and Abad, P. (2016). Gall-forming root-knot nematodes hijack key plant cellular functions to induce multinucleate and hypertrophied feeding cells. J. Insect Physiol. 84, 60-69. doi: 10.1016/j. jinsphys.2015.07.013

Gardner, M., Dhroso, A., Johnson, N., Davis, E. L., Baum, T. J., Korkin, D., et al. (2018). Novel global effector mining from the transcriptome of early life stages of the soybean cyst nematode Heterodera glycines. Sci. Rep. 8:2505. doi: 10.1038/s41598-018-20536-5

Gardner, M., Verma, A., and Mitchum, M. G. (2016). Chapter eleven - emerging roles of cyst nematode effectors in exploiting plant cellular processes. Adv. Bot. Res. 73, 259-291. doi: 10.1016/bs.abr.2014.12.009
Gheysen, G., and Mitchum, M. G. (2019). Phytoparasitic nematode control of plant hormone pathways. Plant Physiol. 179, 1212-1226. doi: 10.1104/pp.18.01067

Goverse, A., and Smant, G. (2014). The activation and suppression of plant innate immunity by parasitic nematodes. Annu. Rev. Phytopathol. 52, 243-265. doi: 10.1146/annurev-phyto-102313-050118

Guo, X., Chronis, D., De La Torre, C. M., Smeda, J., Wang, X., and Mitchum, M. G. (2015). Enhanced resistance to soybean cyst nematode Heterodera glycines in transgenic soybean by silencing putative CLE receptors. Plant Biotechnol. J. 13, 801-810. doi: $10.1111 /$ pbi.12313

Guo, X., Wang, J., Gardner, M., Fukuda, H., Kondo, Y., Etchells, J. P., et al. (2017). Identification of cyst nematode B-type CLE peptides and modulation of the vascular stem cell pathway for feeding cell formation. PLoS Pathog. 13:e1006142. doi: 10.1371/journal.ppat.1006142

Guo, Y., Ni, J., Denver, R., Wang, X., and Clark, S. E. (2011). Mechanisms of molecular mimicry of plant CLE peptide ligands by the parasitic nematode Globodera rostochiensis. Plant Physiol. 157, 476-484. doi: 10.1104/pp.111. 180554

Hamamouch, N., Li, C., Hewezi, T., Baum, T. J., Mitchum, M. G., Hussey, R. S., et al. (2012). The interaction of the novel 30C02 cyst nematode effector protein with a plant $\beta$-1,3-endoglucanase may suppress host defence to promote parasitism. J. Exp. Bot. 63, 3683-3695. doi: 10.1093/jxb/ers058

Hewezi, T. (2015). Cellular signaling pathways and posttranslational modifications mediated by nematode effector proteins. Plant Physiol. 169, 1018-1026. doi: 10.1104/pp.15.00923

Hewezi, T., and Baum, T. J. (2013). Manipulation of plant cells by cyst and rootknot nematode effectors. Mol. Plant Microbe Interact. 26, 9-16. doi: 10.1094/ MPMI-05-12-0106-FI

Hewezi, T., Howe, P., Maier, T. R., Hussey, R. S., Mitchum, M. G., Davis, E. L., et al. (2008). Cellulose binding protein from the parasitic nematode Heterodera schachtii interacts with Arabidopsis pectin methylesterase: cooperative cell wall modification during parasitism. Plant Cell 20, 3080-3093. doi: 10.1105/tpc.108. 063065

Hewezi, T., Howe, P. J., Maier, T. R., Hussey, R. S., Mitchum, M. G., Davis, E. L., et al. (2010). Arabidopsis spermidine synthase is targeted by an effector protein of the cyst nematode Heterodera schachtii. Plant Physiol. 152, 968-984. doi: 10.1104/pp.109.150557

Hewezi, T., Juvale, P. S., Piya, S., Maier, T. R., Rambani, A., Rice, J. H., et al. (2015). The cyst nematode effector protein $10 \mathrm{~A} 07$ targets and recruits host posttranslational machinery to mediate its nuclear trafficking and to promote parasitism in Arabidopsis. Plant Cell 27, 891-907. doi: 10.1105/tpc.114. 135327

Hirsch, S., and Oldroyd, G. E. D. (2009). GRAS-domain transcription factors that regulate plant development. Plant Signal. Behav. 4, 698-700. doi: 10.4161/psb. 4.8.9176

Huang, G., Allen, R., Davis, E. L., Baum, T. J., and Hussey, R. S. (2006). Engineering broad root-knot resistance in transgenic plants by RNAi silencing of a conserved and essential root-knot nematode parasitism gene. Proc. Natl. Acad. Sci. U.S.A. 103, 14302-14306. doi: 10.1073/pnas.0604698103

Huang, G., Dong, R., Allen, R., Davis, E. L., Baum, T. J., and Hussey, R. S. (2007). A root-knot nematodes ecretory peptide functions as a ligand for a plant transcription factor. Mol. Plant Microbe Interact. 19, 463-470. doi: 10.1094/ mpmi-19-0463

Huang, G., Gao, B., Maier, T., Allen, R., Davis, E. L., Baum, T. J., et al. (2003). A profile of putative parasitism genes expressed in the esophageal gland cells of the root-knot nematode Meloidogyne incognita. Mol. Plant Microbe Interact. 16, 376-381. doi: 10.1094/mpmi.2003.16.5.376

Iberkleid, I., Vieira, P., de Almeida Engler, J., Firester, K., Spiegel, Y., and Horowitz, S. B. (2013). Fatty acid-and retinol-binding protein, Mj-FAR-1 induces tomato host susceptibility to root-knot nematodes. PLoS One 8:e64586. doi: 10.1371/ journal.pone.0064586

Jaouannet, M., Nguyen, C.-N., Quentin, M., Jaubert-Possamai, S., Rosso, M.-N., and Favery, B. (2018). In situ Hybridization (ISH) in preparasitic and parasitic stages of the plant-parasitic nematode Meloidogyne spp. Bio Protoc. 8:e2766. doi: 10.21769/BioProtoc.2766

Jaouannet, M., Perfus-Barbeoch, L., Deleury, E., Magliano, M., Engler, G., Vieira, P., et al. (2012). A root-knot nematode-secreted protein is injected into giant cells and targeted to the nuclei. New Phytol. 194, 924-931. doi: 10.1111/j.14698137.2012.04164.x 
Jaubert, S., Milac, A. L., Petrescu, A. J., de Almeida-Engler, J., Abad, P., and Rosso, M.-N. (2005). In planta secretion of a calreticulin by migratory and sedentary stages of root-knot nematode. Mol. Plant Microbe Interact. 18, 1277-1284. doi: 10.1094/MPMI-18-1277

Jones, J. T., Kumar, A., Pylypenko, L. A., Thirugnanasambandam, A., Castelli, L., Chapman, S., et al. (2009). Identification and functional characterization of effectors in expressed sequence tags from various life cycle stages of the potato cyst nematode Globodera pallida. Mol. Plant Pathol. 10, 815-828. doi: 10.1111/j.1364-3703.2009.00585.x

Kazan, K., and Lyons, R. (2014). Intervention of phytohormone pathways by pathogen effectors. Plant Cell 26, 2285-2309. doi: 10.1105/tpc.114.125419

Kumar, M., Gantasala, N. P., Roychowdhury, T., Thakur, P. K., Banakar, P., Shukla, R. N., et al. (2014). De novo transcriptome sequencing and analysis of the cereal cyst nematode, Heterodera avenae. PLoS One 9:e96311. doi: 10.1371/journal. pone.0096311

Kyndt, T., Vieira, P., Gheysen, G., and de Almeida-Engler, J. (2013). Nematode feeding sites: unique organs in plant roots. Planta 238, 807-818. doi: 10.1007/ s00425-013-1923-z

Lee, C., Chronis, D., Kenning, C., Peret, B., Hewezi, T., Davis, E. L., et al. (2011). The novel cyst nematode effector protein $19 \mathrm{C} 07$ interacts with the Arabidopsis auxin influx transporter LAX3 to control feeding site development. Plant Physiol. 155, 866-880. doi: 10.1104/pp.110.167197

Leelarasamee, N., Zhang, L., and Gleason, C. (2018). The root-knot nematode effector MiPFN3 disrupts plant actin filaments and promotes parasitism. PLoS Pathog. 14:e1006947. doi: 10.1371/journal.ppat.1006947

Li, X., Yang, D., Niu, J., Zhao, J., and Jian, H. (2016). De novo analysis of the transcriptome of Meloidogyne enterolobii to uncover potential target genes for biological control. Int. J. Mol. Sci. 17:1442. doi: 10.3390/ijms17091442

Lilley, C. J., Maqbool, A., Wu, D., Yusup, H. B., Jones, L. M., Birch, P. R. J., et al. (2018). Effector gene birth in plant parasitic nematodes: neofunctionalization of a housekeeping glutathione synthetase gene. PLoS Genet. 14:e1007310. doi: 10.1371/journal.pgen. 1007310

Lin, B., Zhuo, K., Chen, S., Hu, L., Sun, L., Wang, X., et al. (2016). A novel nematode effector suppresses plant immunity by activating host reactive oxygen speciesscavenging system. New Phytol. 209, 1159-1173. doi: 10.1111/nph.13701

Lin, B., Zhuo, K., Wu, P., Cui, R., Zhang, L.-H., and Liao, J. (2012). A novel effector protein, MJ-NULGla, targeted to giant cell nuclei plays a role in Meloidogyne javanica Parasitism. Mol. Plant Microbe Interact. 26, 55-66. doi: 10.1094/mpmi05-12-0114-fi

Lozano-Torres, J. L., Wilbers, R. H. P., Gawronski, P., Boshoven, J. C., FinkersTomczak, A., Cordewener, J. H. G., et al. (2012). Dual disease resistance mediated by the immune receptor Cf- 2 in tomato requires a common virulence target of a fungus and a nematode. Proc. Natl. Acad. Sci. U.S.A. 109, 1011910124. doi: 10.1073/pnas.1202867109

Lu, S.-W., Chen, S., Wang, J., Yu, H., Chronis, D., Mitchum, M. G., et al. (2009). Structural and functional diversity of CLAVATA3/ESR (CLE)-like genes from the potato cyst nematode Globodera rostochiensis. Mol. Plant Microbe Interact. 22, 1128-1142. doi: 10.1094/mpmi-22-9-1128

Luo, S., Liu, S., Kong, L., Peng, H., Huang, W., Jian, H., et al. (2019). Two venom allergen-like proteins, HaVAP1 and HaVAP2, are involved in the parasitism of Heterodera avenae. Mol. Plant Pathol. 20, 471-484. doi: 10.1111/mpp.12768

Manosalva, P., Manohar, M., von Reuss, S. H., Chen, S., Koch, A., Kaplan, F., et al. (2015). Conserved nematode signalling molecules elicit plant defenses and pathogen resistance. Nat. Commun. 6:7795. doi: 10.1038/ncomms8795

Masonbrink, R., Maier, T. R., Muppirala, U., Seetharam, A. S., Lord, E., Juvale, P. S., et al. (2019). The genome of the soybean cyst nematode (Heterodera glycines) reveals complex patterns of duplications involved in the evolution of parasitism genes. BMC Genomics 20:119. doi: 10.1186/s12864-019-5485-8

Mei, Y., Wright, K. M., Haegeman, A., Bauters, L., Diaz-Granados, A., Goverse, A., et al. (2018). The Globodera pallida SPRYSEC effector GpSPRY-414-2 that suppresses plant defenses targets a regulatory component of the dynamic microtubule network. Front. Plant Sci. 9:1019. doi: 10.3389/fpls.2018.01019

Misas-Villamil, J. C., van der Hoorn, R. A. L., and Doehlemann, G. (2016). Papainlike cysteine proteases as hubs in plant immunity. New Phytol. 212, 902-907. doi: $10.1111 /$ nph.14117

Mitchum, M. G., Hussey, R. S., Baum, T. J., Wang, X., Elling, A. A., Wubben, M., et al. (2013). Nematode effector proteins: an emerging paradigm of parasitism. New Phytol. 199, 879-894. doi: 10.1111/nph.12323
Mukhtar, M. S., Carvunis, A.-R., Dreze, M., Epple, P., Steinbrenner, J., Moore, J., et al. (2011). Independently evolved virulence effectors converge onto hubs in a plant immune system network. Science 333, 596-601. doi: 10.1126/science. 1203659

Naalden, D., Haegeman, A., de Almeida-Engler, J., Birhane Eshetu, F., Bauters, L., and Gheysen, G. (2018). The Meloidogyne graminicola effector Mg16820 is secreted in the apoplast and cytoplasm to suppress plant host defense responses. Mol. Plant Pathol. 19, 2416-2430. doi: 10.1111/mpp.12719

Nguyen, C. N., Perfus-Barbeoch, L., Quentin, M., Zhao, J., Magliano, M., Marteu, N., et al. (2018). A root-knot nematode small glycine and cysteine-rich secreted effector, MiSGCR1, is involved in plant parasitism. New Phytol. 217, 687-699. doi: $10.1111 /$ nph. 14837

Noon, J. B., Hewezi, T., Maier, T. R., Simmons, C., Wei, J.-Z., Wu, G., et al. (2015). Eighteen new candidate effectors of the phytonematode Heterodera glycines produced specifically in the secretory esophageal gland cells during parasitism. Phytopathology 105, 1362-1372. doi: 10.1094/PHYTO-02-15-0049-R

Opperman, C. H., Bird, D. M., Williamson, V. M., Rokhsar, D. S., Burke, M., Cohn, J., et al. (2008). Sequence and genetic map of Meloidogyne hapla: a compact nematode genome for plant parasitism. Proc. Natl. Acad. Sci. U.S.A. 105, 14802-14807. doi: 10.1073/pnas.0805946105

Palomares-Rius, J. E., Escobar, C., Cabrera, J., Vovlas, A., and Castillo, P. (2017). Anatomical alterations in plant tissues induced by plant-parasitic nematodes. Front. Plant Sci. 8:1987. doi: 10.3389/fpls.2017.01987

Patel, N., Hamamouch, N., Li, C., Hewezi, T., Hussey, R. S., Baum, T. J., et al. (2010). A nematode effector protein similar to annexins in host plants. J. Exp. Bot. 61, 235-248. doi: 10.1093/jxb/erp293

Petitot, A. S., Dereeper, A., Agbessi, M., Da Silva, C., Guy, J., Ardisson, M., et al. (2016). Dual RNA-seq reveals Meloidogyne graminicola transcriptome and candidate effectors during the interaction with rice plants. Mol. Plant Pathol. 17, 860-874. doi: 10.1111/mpp.12334

Pogorelko, G., Juvale, P. S., Rutter, W. B., Hewezi, T., Hussey, R., Davis, E. L., et al. (2016). A cyst nematode effector binds to diverse plant proteins, increases nematode susceptibility and affects root morphology. Mol. Plant Pathol. 17, 832-844. doi: 10.1111/mpp.12330

Pogorelko, G. V., Juvale, P. S., Rutter, W. B., Hütten, M., Maier, T. R., Hewezi, T., et al. (2019). Re-targeting of a plant defense protease by a cyst nematode effector. Plant J. 98, 1000-1014. doi: 10.1111/tpj.14295

Postma, W. J., Slootweg, E. J., Rehman, S., Finkers-Tomczak, A., Tytgat, T. O. G., van Gelderen, K., et al. (2012). The effector SPRYSEC-19 of Globodera rostochiensis suppresses CC-NB-LRR-mediated disease resistance in plants. Plant Physiol. 160, 944-954. doi: 10.1104/pp.112.200188

Quentin, M., Abad, P., and Favery, B. (2013). Plant parasitic nematode effectors target host defense and nuclear functions to establish feeding cells. Front. Plant Sci. 4:53. doi: 10.3389/fpls.2013.00053

Reddy, A. S. N., Marquez, Y., Kalyna, M., and Barta, A. (2013). Complexity of the alternative splicing landscape in plants. Plant Cell 25, 3657-3683. doi: 10.1105/ tpc.113.117523

Rehman, S., Postma, W., Tytgat, T., Prins, P., Qin, L., Overmars, H., et al. (2009). A secreted SPRY domain-containing protein (SPRYSEC) from the plant-parasitic nematode Globodera rostochiensis interacts with a CC-NB-LRR protein from a susceptible tomato. Mol. Plant Microbe Interact. 22, 330-340. doi: 10.1094/ mpmi-22-3-0330

Replogle, A., Wang, J., Bleckmann, A., Hussey, R. S., Baum, T. J., Sawa, S., et al. (2011). Nematode CLE signaling in Arabidopsis requires CLAVATA2 and CORYNE. Plant J. 65, 430-440. doi: 10.1111/j.1365-313X.2010.04433.x

Rodiuc, N., Vieira, P., Banora, M. Y., and de Almeida Engler, J. (2014). On the track of transfer cell formation by specialized plant-parasitic nematodes. Front. Plant Sci. 5:160. doi: 10.3389/fpls.2014.00160

Sacco, M. A., Koropacka, K., Grenier, E., Jaubert, M. J., Blanchard, A., Goverse, A., et al. (2009). The cyst nematode SPRYSEC protein RBP-1 elicits Gpa2- and RanGAP2-dependent plant cell death. PLoS Pathog. 5:e1000564. doi: 10.1371/ journal.ppat.1000564

Shukla, N., Yadav, R., Kaur, P., Rasmussen, S., Goel, S., Agarwal, M., et al. (2018). Transcriptome analysis of root-knot nematode (Meloidogyne incognita)infected tomato (Solanum lycopersicum) roots reveals complex gene expression profiles and metabolic networks of both host and nematode during susceptible and resistance responses. Mol. Plant Pathol. 19, 615-633. doi: 10.1111/mpp. 12547 
Siddique, S., and Grundler, F. M. (2018). Parasitic nematodes manipulate plant development to establish feeding sites. Curr. Opin. Microbiol. 46, 102-108. doi: 10.1016/j.mib.2018.09.004

Singh, S. K., Hodda, M., and Ash, G. J. (2013). Plant-parasitic nematodes of potential phytosanitary importance, their main hosts and reported yield losses. EPPO Bull. 43, 334-374. doi: 10.1111/epp.12050

Sobczak, M., and Golinowski, W. (2011). "Cyst nematodes and syncytia," in Genomics and Molecular Genetics of Plant-Nematode Interactions, eds J. John, G. Godelieve, and F. Carmen (Dordrecht: Springer), 61-82. doi: 10.1007/97894-007-0434-3_4

Szakasits, D., Heinen, P., Wieczorek, K., Hofmann, J., Wagner, F., Kreil, D. P., et al. (2009). The transcriptome of syncytia induced by the cyst nematode Heterodera schachtii in Arabidopsis roots. Plant J. 57, 771-784. doi: 10.1111/j.1365-313X. 2008.03727.x

Truong, N. M., Nguyen, C.-N., Abad, P., Quentin, M., and Favery, B. (2015). Function of root-knot nematode effectors and their targets in plant parasitism. Adv. Bot. Res. 73, 293-324. doi: 10.1016/BS.ABR.2014.12.010

van Schie, C. C. N., and Takken, F. L. W. (2014). Susceptibility genes 101: how to be a good host. Annu. Rev. Phytopathol. 52, 551-581. doi: 10.1146/annurev-phyto102313-045854

Verma, A., Lee, C., Morriss, S., Odu, F., Kenning, C., Rizzo, N., et al. (2018). The novel cyst nematode effector protein 30D08 targets host nuclear functions to alter gene expression in feeding sites. New Phytol. 219, 697-713. doi: 10.1111/ nph.15179

Vieira, P., Danchin, E. G. J., Neveu, C., Crozat, C., Jaubert, S., Hussey, R. S., et al. (2011). The plant apoplasm is an important recipient compartment for nematode secreted proteins. J. Exp. Bot. 62, 1241-1253. doi: 10.1093/jxb/erq352

Vieira, P., and Gleason, C. (2019). Plant-parasitic nematode effectors - insights into their diversity and new tools for their identification. Curr. Opin. Plant Biol. 50, 37-43. doi: 10.1016/j.pbi.2019.02.007

Vijayapalani, P., Hewezi, T., Pontvianne, F., and Baum, T. J. (2018). An effector from the cyst nematode Heterodera schachtii derepresses host rRNA genes by altering histone acetylation. Plant Cell 30, 2795-2812. doi: 10.1105/tpc.18. 00570

Wang, J., Lee, C., Replogle, A., Joshi, S., Korkin, D., Hussey, R., et al. (2010). Dual roles for the variable domain in protein trafficking and host-specific recognition of Heterodera glycines CLE effector proteins. New Phytol. 187, 1003-1017. doi: 10.1111/j.1469-8137.2010.03300.x

Wang, X. R., Moreno, Y. A., Wu, H. R., Ma, C., Li, Y. F., Zhang, J. A., et al. (2012). Proteomic profiles of soluble proteins from the esophageal gland in female Meloidogyne incognita. Int. J. Parasitol. 42, 1177-1183. doi: 10.1016/j. ijpara.2012.10.008

Weiberg, A., Wang, M., Lin, F.-M., Zhao, H., Zhang, Z., Kaloshian, I., et al. (2013). Fungal small RNAs suppress plant immunity by hijacking host RNA interference pathways. Science 342, 118-123. doi: 10.1126/science.1239705
Weßling, R., Epple, P., Altmann, S., He, Y., Yang, L., Henz, S. R., et al. (2014). Convergent targeting of a common host protein-network by pathogen effectors from three kingdoms of life. Cell Host Microbe 16, 364-375. doi: 10.1016/j. chom.2014.08.004

Xue, B., Hamamouch, N., Li, C., Huang, G., Hussey, R. S., Baum, T. J., et al. (2013). The 8D05 parasitism gene of Meloidogyne incognita is required for successful infection of host roots. Phytopathology 103, 175-181. doi: 10.1094/PHYTO-0712-0173-R

Yang, D., Chen, C., Liu, Q., and Jian, H. (2017). Comparative analysis of preand post-parasitic transcriptomes and mining pioneer effectors of Heterodera avenae. Cell Biosci. 7:11. doi: 10.1186/s13578-017-0138-6

Yang, S., Pan, L., Chen, Y., Yang, D., Liu, Q., and Jian, H. (2019). Heterodera avenae GLAND5 effector interacts with Pyruvate Dehydrogenase Subunit of plant to promote nematode parasitism. Front. Microbiol. 10:1241. doi: 10.3389/fmicb. 2019.01241

Yang, S., Tang, F., and Zhu, H. (2014). Alternative splicing in plant immunity. Int. J. Mol. Sci. 15, 10424-10445. doi: 10.3390/ijms150610424

Yang, Y., Jittayasothorn, Y., Chronis, D., Wang, X., Cousins, P., and Zhong, G. Y. (2013). Molecular characteristics and efficacy of 16D10 siRNAs in inhibiting root-knot nematode infection in transgenic grape hairy roots. PLoS One 8:e69463. doi: 10.1371/journal.pone.0069463

Zaidi, S. S.-A., Mukhtar, M. S., and Mansoor, S. (2018). Genome editing: targeting susceptibility genes for plant disease resistance. Trends Biotechnol. 36, 898-906. doi: 10.1016/J.TIBTECH.2018.04.005

Zhang, L., Davies, L. J., and Elling, A. A. (2015). A Meloidogyne incognita effector is imported into the nucleus and exhibits transcriptional activation activity in planta. Mol. Plant Pathol. 16, 48-60. doi: 10.1111/mpp.12160

Zhao, J., Li, L., Liu, Q., Liu, P., Li, S., Yang, D., et al. (2019). A MIF like effector of Meloidogyne incognita suppresses plant immunity and assists parasitism by interacting with annexins. J. Exp. Bot. (in press).

Zhuo, K., Naalden, D., Nowak, S., Xuan Huy, N., Bauters, L., and Gheysen, G. (2019). A Meloidogyne graminicola C-type lectin, Mg01965, is secreted into the host apoplast to suppress plant defence and promote parasitism. Mol. Plant Pathol. 20, 346-355. doi: 10.1111/mpp.12759

Conflict of Interest Statement: The authors declare that the research was conducted in the absence of any commercial or financial relationships that could be construed as a potential conflict of interest.

Copyright (C) 2019 Mejias, Truong, Abad, Favery and Quentin. This is an open-access article distributed under the terms of the Creative Commons Attribution License (CC BY). The use, distribution or reproduction in other forums is permitted, provided the original author(s) and the copyright owner(s) are credited and that the original publication in this journal is cited, in accordance with accepted academic practice. No use, distribution or reproduction is permitted which does not comply with these terms. 